\title{
STUDI PERBANDINGAN PENGARUH BERBAGAI WARNA LAMPU DAN BUNYI TERHADAP PERTUMBUHAN SAYURAN SAWI HIJAU (Brassica Rapa Var. Parachinensis L)
}

\author{
Musdarina, Hernawati, dan Fitriyanti ${ }^{1}$ \\ 1Jurusan Fisika, Fakultas Sains dan Teknologi, UIN Alauddin Makassar \\ Email: hernawati@uin-alauddin.ac.id, fitriyanti_fisika@uin-alauddin.ac.id
}

\begin{abstract}
Research has been conducted which aims to determine the effect of various colors of LED light and sound effects with frequency of $280 \mathrm{~Hz}-16 \mathrm{KHz}$. This research was conducted by seeding mustard greens for 2 weeks then moving mustard greens to polybags by giving two treatments. First treatment of mustard greens illuminated by LED lights with the color red, yellow, green and the fourth polybag left without the addition of LED light. The second treatment is every 1 polybag of green mustard illuminated by LED lights with red, yellow, green lights at night for 4 hours then exposed to sound in the morning for 4 hours and the fourth polybag is exposed to sound without the addition of lights. The results of this study indicate the effect of the addition of red LED light color on the plant is clearly seen in the width of green mustard leaves that have wider leaves between the addition of other LED light colors and the number of leaves produced more than the addition of yellow, green and without additional light. The effect of exposure to sound on the plant has a fairly good influence on the height of the stem, stem width and number of leaves compared to plants that are not given sound exposure and in plants that are given additional LED light then the sound produces better plant growth compared to plants that only given additional lights or just given a sound.
\end{abstract}

Keywords: Light, Sound, LED Light, Green Mustard.

\section{PENDAhuluan}

Sawi hijau (Brassica rapa var. parachinensis $L$ ) merupakan tanaman sayuran yang mempunyai nilai ekonomis tinggi dan digemari masyarakat Indonesia. Masa panen singkat, pengadaan bibit terjangkau dan pemeliharaan yang tidak rumit merupakan daya tarik untuk membudidayakan tanaman sawi. Konsumen sawi diduga akan mengalami peningkatan sesuai pertumbuhan jumlah penduduk dan peningkatan pengetahuan gizi masyarakat mengenai sawi.

Sejauh ini petani tradisional menanam sawi di lingkungan terbuka. Akibatnya saat musim hujan banyak tanaman yang terpukul air hujan dan terserang penyakit. Sedangkan pada musim kemarau, kualitasnya turun karena daun sawi dimakan oleh serangga. Masalah ini dapat di minimalisir dengan penanaman sawi dalam rumah tanam. Selain mampu menahan pukulan air hujan dan serangan hama, bangunan ini 
juga dapat mengoptimalkan penambahan cahaya tambahan dan penerapan sonic bloom.

Seiring perkembangan teknologi pemanfaatan media penerangan dan bunyi merupakan salah satu alternatif yang baik agar pertumbuhan tanaman dapat berlangsung lebih cepat, bermutu tinggi dan meningkatkan jumlahnya. Oleh karena itu dalam penelitian ini digunakan cahaya tambahan dengan warna yang berbedabeda dimana masing-masing warna cahaya memiliki rentang panjang gelombang tertentu yang mampu diserap oleh tanaman.

Pada penelitian Ernawati, dkk (2011) dapat disimpulkan bahwa penambahan pencahayaan dengan warna yang berbeda-beda dapat mempengaruhi pertumbuhan lebar daun tanaman maupun waktu panen tumbuhan tersebut. Penambahan cahaya buatan juga dapat mempercepat proses fotosintesis sehingga tanaman lebih cepat berkembang. Penambahan cahaya pada tumbuhan diharapkan dapat mengefesiensikan waktu seseorang dalam proses penanamannya.

Menurut Handoko dan Fajariyanti (2008), sinar matahari menghasilkan cahaya polikromatik yang dapat dibiaskan menjadi cahaya monokromatik. Cahaya monokromatik inilah yang digunakan tanaman untuk berfotosintesis. Klorofil mampu menangkap cahaya monokromatik dari matahari pada panjang gelombang tertentu. Cahaya yang mampu diserap tanaman pada kisaran panjang gelombang antara 400 sampai $700 \mathrm{~nm}$. Klorofil berfungsi dengan baik dalam proses fotosintesis pada panjang gelombang $660 \mathrm{~nm}$ pada sinar merah dan paling buruk pada panjang gelombang $430 \mathrm{~nm}$ pada sinar biru. Sinar kuning dan hijau dipantulkan tanaman, namun jika diteruskan kembali ke tanaman akan terserap dan mampu membantu proses fotosintesis.

Selain menggunakan cahaya dalam meningkatkan produktivitas tanaman, salah satu teknologi pertanian yang banyak dikembangkan yaitu dengan penerapan sonic bloom. Sonic bloom merupakan suatu teknologi organik yang memanfaatkan gelombang suara berfrekuensi tinggi untuk meningkatkan produktivitas tanaman. Teknologi ini bekerja dengan mengoptimalkan pembukaan stomata pada frekuensi suara tertentu.

Menurut Yulianto (2008), Penerapan Sonic bloom dapat menyuburkan pertumbuhan tanaman dengan menggunakan gelombang suara frekuensi tinggi (3500-5000 Hertz) yang digabungkan dengan pemberian nutrisi. Gelombang suara dengan frekuensi tinggi dalam menghasilkan energi yang mampu memberi tegangan negatif terhadap stomata sehingga merangsang mulut daun (stomata) tetap terbuka sehingga dapat meningkatkan laju dan efesiensi penyerapan pupuk pada daun (Yulianto, 2008). 


\section{METODE PENELITIAN}

Prosedur kerja pada penelitian ini terdiri dari beberapa tahap, yaitu menyiapkan alat dan bahan, pengujian luminesensi, dan prosedur penanaman.

\section{Pengujian luminesensi}

Prosedur kerja untuk pengujian luminesensi untuk mengetahui intensitas yang akan digunakan adalah sebagai berikut: memasang lampu yang akan digunakan dengan cara digantungkan, meletakkan alat ukur lux meter tepat dibawah lampu yang telah terpasang dengan aliran listrik, menyalakan lampu dan mengatur posisi tinggi rendahnya lampu seseuai intensitas cahaya yang diingikan, mengamati penunjukkan intensitas cahaya pada alat ukur lux meter.

\section{Prosedur Penanaman}

Hal yang pertama dilakukan dalam penanaman adalah menyiapkan benih sawi. Selanjutnya membuat media tanam dengan cara mencampurkan tanah dan pupuk kandang dengan perbandingan 2:1 kemudian di remas hingga merata. Media tanah yang halus di masukkan ke dalam polybag atau pot. Benih sawi disemai ke dalam polybag atau pot berukuran sedang. Jika sudah maka dapat disiram dengan air agar kelembaban benih dapat terjaga. Setelah benih sawi tumbuh selama 2 minggu maka di pindahkan pada polybag yang ukurannya lebih besar. Tahap pemindahan bibit dilakukan dengan cara yang sama pada saat proses penyemaian yaitu media tanah dan pupuk kandang dicampur terlebih dahulu lalu bibit dimasukkan ke dalamnya. Jika sudah dapat di siram dengan air agar kelembaban sayur dapat terjaga. Sayur sawi dalam polybag dapat dipindahkan pada rak tanaman dengan memberikan perlakuan intensitas cahaya yang cukup. Tanaman diberikan cahaya tambahan saat matahari mulai terbenam jam $18.00-22.00$ WITA. Setiap tanaman disinari dengan warna pencahayaan yang berbeda-beda dan tanpa pencahayaan. Pada pagi hari tanaman diberikan frekuensi bunyi mulai pukul 06.0010.00 WIB. Tanaman yang pada waktu malam hari disinari cahaya lampu,pada pagi hari dipaparkan bunyi dan tanaman yang hanya diberi paparan bunyi. Gambar 1 menunjukan tanaman sawi pada malam hari dan siang hari. 


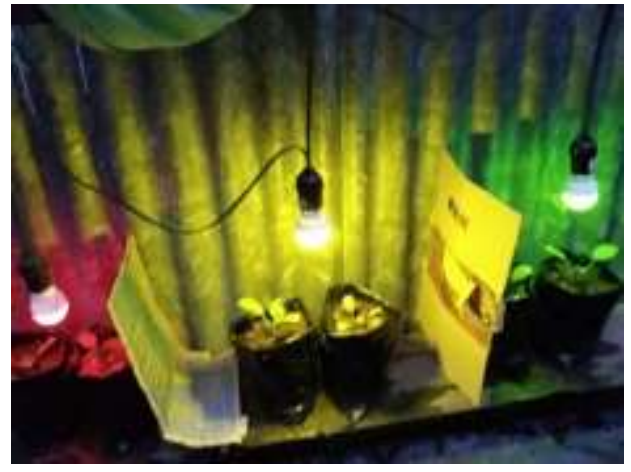

(a)

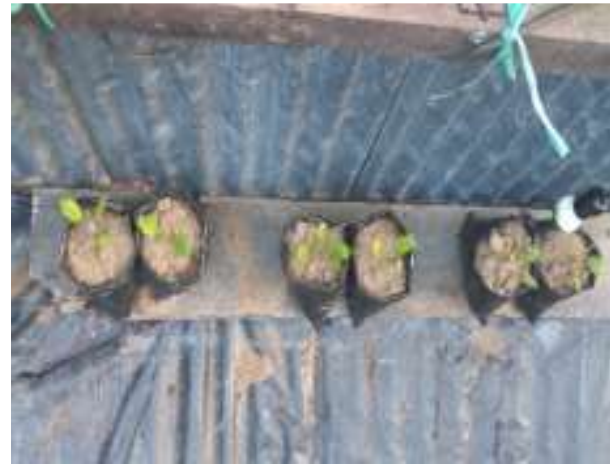

(b)

Gambar 1. (a)Tanaman sawi pada malam hari, (b)Tanaman sawi pada siang hari

\section{HASIL DAN PEMBAHASAN}

Pengaruh warna cahaya lampu pada pertumbuhan lebar daun, jumlah daun, diameter batang dan tinggi batang tanaman sawi hijau

Hasil penelitian yang diperoleh dari pengambilan data secara tunggal terhadap pengukuran pertumbuhan sawi hijau yang telah dilakukan selama 4 minggu dapat dilihat pada tabel 1 berikut ini:

Tabel 1. Hasil pertumbuhan setiap minggu dengan berbagai warna cahaya

\begin{tabular}{|c|c|c|c|c|c|c|c|}
\hline $\mathrm{NO}$ & Waktu & $\begin{array}{l}\text { Suhu } \\
\left({ }^{\circ} \mathrm{C}\right)\end{array}$ & $\begin{array}{l}\text { Warna } \\
\text { Lampu }\end{array}$ & $\begin{array}{c}\text { Lebar } \\
\text { Daun } \\
(\mathrm{cm})\end{array}$ & $\begin{array}{c}\text { Jumlah } \\
\text { Daun }\end{array}$ & $\begin{array}{c}\text { Lebar } \\
\text { Batang } \\
\text { (cm) }\end{array}$ & $\begin{array}{c}\text { Tinggi } \\
\text { Batang } \\
(\mathrm{cm})\end{array}$ \\
\hline \multirow{4}{*}{1} & \multirow{4}{*}{$\begin{array}{l}\text { Minggu } \\
\text { Pertama }\end{array}$} & \multirow{4}{*}{31} & Merah & 2,1 & 4 & 0,2 & 3,1 \\
\hline & & & Kuning & 2,0 & 4 & 0,2 & 3 \\
\hline & & & Hijau & 2,2 & 4 & 0,2 & 3 \\
\hline & & & $\begin{array}{l}\text { Tanpa } \\
\text { Lampu }\end{array}$ & 2,1 & 4 & 0,2 & 2,5 \\
\hline \multirow{4}{*}{2} & \multirow{4}{*}{$\begin{array}{c}\text { Minggu } \\
\text { Kedua }\end{array}$} & \multirow{4}{*}{29} & Merah & 2,5 & 6 & 0,2 & 3,8 \\
\hline & & & Kuning & 2,5 & 4 & 0,2 & 3,5 \\
\hline & & & Hijau & 2,7 & 5 & 0,3 & 3,2 \\
\hline & & & Tanpa Lmpu & 3,2 & 6 & 0,3 & 4 \\
\hline \multirow{4}{*}{3} & \multirow{4}{*}{$\begin{array}{c}\text { Minggu } \\
\text { Ketiga }\end{array}$} & \multirow{4}{*}{32} & Merah & 6,5 & 7 & 0,5 & 5 \\
\hline & & & Kuning & 5,1 & 7 & 0,5 & 4,5 \\
\hline & & & Hijau & 6,0 & 7 & 0,5 & 5,5 \\
\hline & & & Tanpa Lmpu & 6,2 & 7 & 1 & 5,3 \\
\hline \multirow{4}{*}{4} & \multirow{4}{*}{$\begin{array}{l}\text { Minggu } \\
\text { Keempat }\end{array}$} & \multirow{4}{*}{29} & Merah & 10,6 & 10 & 1,1 & 8 \\
\hline & & & Kuning & 10,1 & 8 & 1 & 7,5 \\
\hline & & & Hijau & 9,7 & 9 & 1,1 & 8 \\
\hline & & & Tanpa Lmpu & 9,5 & 9 & 1,1 & 10 \\
\hline
\end{tabular}


Berdasarkan tabel 1 dapat dilihat bahwa lebar daun yang diperoleh pada setiap batang memiliki lebar yang berbeda pada setiap lampu, yaitu tanaman yang menggunakan cahaya lampu warna dengan tanaman yang tidak menggunakan cahaya lampu dapat dilihat pertumbuhan lebar daun paling besar yaitu pada tanaman yang menggunakan cahaya lampu tambahan warna merah, sedangkan tanaman yang paling lambat dalam pertumbuhan lebar daun yaitu pada tanaman yang menggunakan cahaya lampu warna kuning. Pertumbuhan jumlah daun dari setiap batang tidak jauh berbeda, dimana pertumbuhan daun yang paling cepat masih sama halnya dengan pertumbuhan lebar daunnya, yaitu tanaman bayam yang menggunakan cahaya lampu tambahan warna merah, dengan jumlah daun 10 helai dan 8 helai untuk daun yang tidak menggunakan cahaya tambahan. Pertumbuhan lebar batang dari data yang diperoleh tidak jauh berbeda satu sama lain dimana pertumbuhan lebar batang yang paling lambat yaitu pada tanaman sawi yang menggunakan cahaya lampu tambahan warna kuning, dan pada tanaman sawi yang tidak menggunakan cahaya tambahan lebih lebar. Pada tinggi batang diperoleh hasil yang berbeda dengan hasil dari pertumbuhan lebar daun dan jumlah daun yaitu, tanaman yang tidak menggunakan cahaya lampu tambahan lebih cepat tinggi dibandingkan dengan tanaman yang menggunakan cahaya lampu warna hijau, kuning ataupun tanaman yang menggunakan cahaya lampu warna merah.

Pengaruh warna cahaya lampu pada pertumbuhan lebar daun, jumlah daun, lebar batang dan tinggi batang tanaman sawi hijau yang dipaparkan bunyi

Hasil dari penelitian yang diperoleh dari pengambilan data secara tunggal terhadap pengukuran pertumbuhan sawi hijau yang telah dilakukan selama 4 minggu dapat dilihat pada tabel 2 berikut ini :

Tabel 2. Hasil Pengukuran pertumbuhan sawi hijau setiap minggu dengan berbagai warna yang dipaparkan bunyi

\begin{tabular}{|l|l|l|l|l|l|l|l|}
\hline NO & \multirow{2}{*}{ Waktu } & $\begin{array}{l}\text { Suhu } \\
\left({ }^{\circ} \mathrm{C}\right)\end{array}$ & Warna Lampu & $\begin{array}{l}\text { Lebar } \\
\text { Daun } \\
(\mathrm{cm})\end{array}$ & $\begin{array}{l}\text { Jumlah } \\
\text { Daun }\end{array}$ & $\begin{array}{l}\text { Lebar } \\
\text { Batang } \\
(\mathrm{cm})\end{array}$ & $\begin{array}{l}\text { Tinggi } \\
\text { Batang } \\
(\mathrm{cm})\end{array}$ \\
\hline \multirow{3}{*}{1} & \multirow{3}{*}{$\begin{array}{l}\text { Minggu } \\
\text { Pertama }\end{array}$} & \multirow{3}{*}{31} & Merah & 2,2 & 4 & 0,2 & 3 \\
\hline \multirow{3}{*}{2} & \multirow{3}{*}{$\begin{array}{l}\text { Minggu } \\
\text { Kedua }\end{array}$} & \multirow{3}{*}{29} & Kuning & 2,2 & 4 & 0,2 & 3 \\
\hline & & Hijau & 2,3 & 4 & 0,2 & 3,2 \\
\hline & & Bunyi & 2,3 & 4 & 0,2 & 3 \\
\hline & & Merah & 4,2 & 9 & 0,4 & 4 \\
\hline & & Kuning & 3,5 & 7 & 0,3 & 3 \\
\hline & & Hijau & 4,2 & 7 & 0,3 & 4 \\
\hline & & Bunyi & 3,8 & 6 & 0,3 & 3,8 \\
\hline
\end{tabular}




\begin{tabular}{|c|c|c|c|c|c|c|c|}
\hline \multirow{4}{*}{3} & \multirow{4}{*}{$\begin{array}{l}\text { Minggu } \\
\text { Ketiga }\end{array}$} & \multirow{4}{*}{32} & Merah & 8,5 & 10 & 1 & 7 \\
\hline & & & Kuning & 7,2 & 7 & 0,5 & 5 \\
\hline & & & Hijau & 7,5 & 8 & 0,5 & 4,5 \\
\hline & & & Bunyi & 8,2 & 9 & 0,5 & 5 \\
\hline \multirow{4}{*}{4} & \multirow{4}{*}{$\begin{array}{l}\text { Minggu } \\
\text { Keempat }\end{array}$} & \multirow{4}{*}{29} & Merah & 13 & 12 & 1,1 & 8,5 \\
\hline & & & Kuning & 11,2 & 10 & 1,1 & 7,5 \\
\hline & & & Hijau & 11,2 & 10 & 1,1 & 7,5 \\
\hline & & & Bunyi & 11 & 12 & 1,1 & 9 \\
\hline
\end{tabular}

Pada tabel 2 menunjukkan bahwa pengaruh cahaya tambahan dan pemaparan bunyi pada lebar daun tanaman sawi hijau direspon baik pada tanaman sawi hijau terutama pada cahaya tambahan warna merah yang memiliki lebar daun $13 \mathrm{~cm}$, sedangakan respon pada tanaman sawi hijau yang tidak diberi cahaya tambahan hanya memiliki lebar daun $10,5 \mathrm{~cm}$. Jumlah daun yang dihasilkan tanaman yang menggunakan cahaya tambahan warna merah dan yang tidak menggunkan cahaya tambahan memiliki jumlah daun yang lebih banyak dibandingkan dengan tanaman yang menggunakan cahaya lampu warna kuning dan hijau. Hal ini seperti yang dijelaskan dalam teori bahwa panjang gelombang suatu pancaran cahaya dapat mempengaruhi pigmen daun, sehingga daun yang dihasilkan nampak perbedaan warna dimana pada cahaya tambahan lampu hijau dan merah terlihat lebih segar dibandingkan daun yang diberikan cahaya lampu kuning dan tanaman yang hanya dipaparkan bunyi. Pertumbuhan lebar batang dari data yang diperoleh sama pada minggu terakhir dimana pertumbuhan lebar batang ini dipengaruhi oleh usia tanaman yang maksimal 45 hari setelah tanam sehingga hasil pengukuran yang diperoleh sama sedangkan hasil pengukuran pada minggu ketiga dan minggu keempat terdapat perbedaan.

Pertumbuhan tinggi batang tanaman sawi hijau yang hanya menggunakan paparan bunyi tanpa cahaya tambahan memiliki tinggi batang lebih tinggi yaitu $9 \mathrm{~cm}$ dibandingkan dengan tanaman yang menggunakan cahaya tambahan. Pertumbuhan tinggi batang ini agak berbeda dari pertumbuhan tanaman sawi berdasarkan lebar daun dimana sawi hijau yang diberikan cahaya tambahan warna merah lebih unggul dibandingkan sawi sawi hijau yang tidak diberikan bunyi.

Berdasarkan penelitian yang telah dilakukan dengan menggunakan benih tanaman sawi hijau diperoleh hasil pertumbuhan sawi hijau lebih cepat berkembang jika menggunakan cahaya tambahan yang disertakan dengan pemaparan bunyi dibandingkan pertumbuhan tanaman sawi hijau yang normal tanpa bantuan cahaya buatan ataupun bantuan dengan pemaparan bunyi.

Pertumbuhan sawi hijau yang diperdengarkan murottal al-quraan menglami pertumbuhan yang relatif pesat dibanding yang lain. Hasil ini sesuai dengan 
literatur yang mengatakan bahwa frekuensi musik yang sesuai pada tanaman akan memberikan dampak yang positif. Sebuah bunyi memiliki frekuensi tertentu yang dibutuhkan stomata pada pertumbuhan untuk terbuka (Tjitrosoma,1984) "Ketika suara dengan frekuensi tertentu dimainkan pada tumbuhan, stomata tumbuhan akan terbuka". Terbukanya stomata menyebabkan penyerapan air lebih efektif sehingga pertumbuhan sawi hijau dapat berkembang dengan baik.

Di dalam musik yang sehat terjadi keseimbangan antara tiga komponen tersebut. Untuk musik murottal Al-Quran dalam pembacaan tiap ayat-ayatnya dengan baik mengandung dampak positif melebihi musik lainnya, karena dalam pembacaan ayat-ayat alquran yang baik dan benar memiliki tekanan tajwid yang variatif dengan frekuensi tertentu sehingga menyebabkan panjang gelombang yang berbeda. Hal ini ditangkap positif oleh tanaman karena pembacaan ayat-ayat alquran memliki ritme yang halus dan selaras sehingga membawa ketenangan, kemudian juga diiringi dengan melodi yang memperindah setiap bacaanya, harmoni yang dihasilkan membawa ketenangan.

Pertumbuhan sawi hijau berdasarkan jumlah daun pada pencahayaan lampu merah pada minggu pertama didapatkan ukuran $2,1 \mathrm{~cm}$, sedangkan pertumbuhan sawi hijau dengan pencahayaan lampu merah yang disertakan bunyi lebih lebar dengan hasil pengukuran $2.2 \mathrm{~cm}$. sampai pada minggu keempat lebar sawi hijau yang menggunakan tambahan pencahayaan lampu merah yang disertakan bunyi lebih lebar dibandingkan pertumbuhan sawi hijau yang lain.

Berdasarkan tabel 3 dapat dilihat bahwa pertumbuhan sawi hijau dengan cahaya tambahan dan sawi hijau dengan cahaya tambahan disertakan paparan bunyi pada minggu ke empat mengalami perubahan dari segi pertumbuhan lebar daun, jumlah daun, lebar batang dan tinggi batang tanaman. Pertumbuhan tanaman ini dipengaruhi oleh beberapa faktor diantaranya panjang gelombang cahaya lampu yang digunakan serta faktor lain seperti suhu dan kelembaban tanah.

Tabel 3. Perbandingan pertumbuhan sawi hijau dengan cahaya tambahan dan sawi hijau dengan cahaya tambahan disertakan bunyi setiap minggu

\begin{tabular}{|l|l|l|l|l|l|l|l|l|}
\hline \multirow{2}{*}{$\begin{array}{l}\text { Penga } \\
\text { matan }\end{array}$} & \multicolumn{3}{|l|}{ Sawi Hijau } & \multicolumn{3}{l|}{ Sawi hijau disertakan bunyi } \\
\cline { 2 - 8 } & $\begin{array}{l}\text { Tanp } \\
\text { Lamp } \\
\mathrm{u}\end{array}$ & $\begin{array}{l}\text { Lampu } \\
\text { Merah }\end{array}$ & $\begin{array}{l}\text { Lampu } \\
\text { Hijau }\end{array}$ & $\begin{array}{l}\text { Lampu } \\
\text { Kuning }\end{array}$ & Bunyi & $\begin{array}{l}\text { Lampu } \\
\text { Merah }\end{array}$ & $\begin{array}{l}\text { Lampu } \\
\text { Hijau }\end{array}$ & $\begin{array}{l}\text { Lampu } \\
\text { Kuning }\end{array}$ \\
\hline $\begin{array}{l}\text { Tinggi } \\
\text { Sawi }\end{array}$ & $\begin{array}{l}10 \\
\mathrm{~cm}\end{array}$ & $8 \mathrm{~cm}$ & $8 \mathrm{~cm}$ & $7,5 \mathrm{~cm}$ & $9 \mathrm{~cm}$ & $13 \mathrm{~cm}$ & $8.5 \mathrm{~cm}$ & $7,5 \mathrm{~cm}$ \\
\hline
\end{tabular}




\begin{tabular}{|c|c|c|c|c|c|c|c|c|}
\hline $\begin{array}{l}\text { Lebar } \\
\text { Sawi }\end{array}$ & $\begin{array}{l}9,5 \\
\mathrm{~cm}\end{array}$ & $\begin{array}{l}10,6 \\
\mathrm{~cm}\end{array}$ & $10 \mathrm{~cm}$ & $10 \mathrm{~cm}$ & $\begin{array}{l}11 \\
\mathrm{~cm}\end{array}$ & $13 \mathrm{~cm}$ & $\begin{array}{l}11,2 c \\
m\end{array}$ & $\begin{array}{l}10,5 \\
\mathrm{~cm}\end{array}$ \\
\hline $\begin{array}{l}\text { Jumlah } \\
\text { Daun }\end{array}$ & 9 & 10 & 9 & 8 & 12 & 12 & 10 & 10 \\
\hline $\begin{array}{l}\text { Lebar } \\
\text { Batang }\end{array}$ & $\begin{array}{l}1,1 \mathrm{c} \\
\mathrm{m}\end{array}$ & $1,1 \mathrm{~cm}$ & $1.1 \mathrm{~cm}$ & $1 \mathrm{~cm}$ & $\begin{array}{l}1,1 \mathrm{c} \\
\mathrm{m}\end{array}$ & $1.1 \mathrm{~cm}$ & $1,1 \mathrm{~cm}$ & $1,1 \mathrm{~cm}$ \\
\hline $\begin{array}{l}\text { Suhu } \\
\text { Rata- } \\
\text { rata }\end{array}$ & $30^{\circ} \mathrm{C}$ & & & & & & & \\
\hline
\end{tabular}

Penambahan cahaya pada tanaman dilakukan pada malam atau sore hari karena untuk menambah proses fotosintesis pada tanaman sehingga tanaman akan semakin produktif secara ekonomi. Akan tetapi agar tumbuh secara sehat, tanaman sebaiknya disinari matahari atau lampu LED dengan total penyinaran tidak melampui 14-16 jam setiap harinya, hal ini dikarenakan agar tanaman tidak pucat atau layu. Penggunaan lampu yang tidak sesuai dan waktu yang terlalu lama dapat mempengaruhi pertumbuhan tanaman, adapun faktor yang dapat mempengaruhi pertumbuhan tanaman diantara nya yaitu faktor suhu, tanah dan persediaan air. Suhu pada tempat penelitian ini yaitu berkisar $28-30^{\circ} \mathrm{C}$ pada pagi hari, pada siang hari hingga petang mencapai $29-35^{\circ} \mathrm{C}$ dan pada malam hari relative dingin yaitu 25 $30^{\circ} \mathrm{C}$.

Musik dengan frekuensi tertentu dimainkan pada tumbuhan, stomata tumbuhan akan terbuka. Terbukanya stomata akan menyebabkan penyerapan pupuk yang lebih efisien daripada tumbuhan tanpa dimainkan musik. Penyerapan pupuk yang baik diikuti dengan tumbuh kembang tanaman yang lebih baik sehingga menyebabkan tumbuhan yang didengarkan musik berkembang lebih baik

Pada penelitian ini penambahan cahaya buatan memiliki pengaruh terhadap pertumbuhan tanaman sayuran sawi hijau dimana yang berpengaruh baik yaitu cahaya lampu LED warna merah dan pemaparan bunyi (murottal) memiliki pengaruh yang cukup baik. Untuk tanaman yang diberi perlakuan penambahan cahaya kemudian dipaparkan musik memiliki pengaruh yang lebih baik dibandingkan dengan penambahan cahaya saja ataupun penambahan pemaparan bunyi saja, hal ini karena penamabahan cahaya dan bunyi berpengaruh positif dalam merangsang stomata untuk tetap berfotosintesis.

\section{KESIMPULAN}

Berdasarkan penelitian yang dilakukan dapat disimpulkan bahwa pengaruh penambahan warna cahaya merah pada tanaman terlihat jelas pada lebar daun sawi hijau yang memiliki daun paling lebar diantara warna cahaya yang lain dan jumlah daun yang dihasilkan lebih banyak dari penambahan warna cahaya kuning, hijau dan tanpa cahaya tambahan. Pemaparan bunyi pada tanaman memiliki pengaruh 
yang cukup baik pada tinggi batang, lebar batang dan jumlah daun dibandingkan dengan tanaman yang tidak diberikan paparan bunyi. Pada tanaman yang diberi tambahan cahaya dan dipaparkan bunyi menghasilakn pertumbuhan tanaman yang lebih baik dibandingkan dengan tanaman yang hanya diberi tambahan lampu atau hanya diberi bunyi saja.

\section{DAFTAR PUSTAKA}

Ad-Dihami. 2005. Menjaga Hati Cetakan Kesatu. Jakarta: Ema Insani

Asti. 2009. Pengaruh Al-Qur'an terhadap Fisiologi dan Psikologi. http://cybermg.com diakses pada 29 Maret 2018.

Cahyono, B. 2003. Teknik dan Strategi Budidaya Sawi Hijau (Pai-Tsai). Hal 1262. Yogyakarta : Yayasan Pustaka Nusatama

Dalimunthe Afifuddin. 2004. Stomata Biosintesis, Mekanisme Kerja dan Peranannya. Program Studi Kehutanan Fakultas Pertanian Universitas Sumatera Utara.

Dhani. 2003. Musik Klasik . http://blog.dhani.org diakses pada 29 Maret 2018.

Dwidjoseputro,D. 1990. Pengantar Fisiologi Tumbuhan. Gramedia Pustaka Utama, Jakarta.

Edi dan Yusri. 2010. Budidaya Sawi Hijau. Jurnal Agrisistem. Balai Pengkajian Teknologi Pertanian Jambi. Jambi.

Fathur, 2010. Musik Rock. http://www.rollitup.org/advanced-marijuanacultivation/294405-influence-music-rock.html diakses pada 29 Maret 2018.

Fitter A. H. dan Hay R. K. M. 1991. Fisiologi Lingkungan Tanaman. Yogyakarta: Gadjah Mada University Press.

Gunawan, L. W. 1992. Teknik Kultur Jaringan Tanaman. Departemen Pendidikan Tinggi Pusat Antar Universitas Bioteknologi Insitut Pertanian Bogor: Bogor I \& F.

Handoko, P., dan Y. Fajariyanti. 2008. Pengaruh Spektrum Cahaya Tampak Terhadap Laju Fotosintesis Tanaman Air Hydrilla Verticillata. Jurnal Prodi Pendidikan Biologi FKIP. Universitas Nusantara PGRI. Kediri

Haryanto Eko,dkk. 2003. Sawi dan Selada. Jakarta: Penebar Swadaya.

Haryanto, E. Tina, S, dan Estu, R. 1995. Sawi dan Selada. Penebar Swadaya. Jakarta. $117 \mathrm{hlm}$ 
Hill, Amelia. 2010. Does Music Affect Plant Growth? .http://www.suite101.com/content/does-music-affect-plant-growtha282993 diakses pada 29 Maret 2018.

Jberry. 2010. Influence of Music on Plants. http://www.rollitup.org/advancedmarijuana-cultivation/294405-influence-music-plants.html diakses pada 29 Maret 2018

Kadisman Nur. 2011. Peningkatan Laju Pertumbuhan Dan Produktivitas Tanaman Kentang (Solonum Tuberosum L.) Melalui Spesifikasi Variabel Fisis Gelombang Akustik Pada Pemupukan Daun (Melalui Perlakuan Variasi Peak Frekuensi), Prosiding Seminar Nasional Penelitian, Pendidikan Dan Penerapan MIPA,UNY.

Kementrian Agama RI. 2017. Al-Qur'an dan Terjemahannya. Dua Ribu Wisata : Jakarta

Latifah, S. 2004. Pertumbuhan Dimensi Tegakan Durian (Durio Zibethinus Murr) Bersama Teknologi Gelombang Suara (Sonic Bloom). Laporan Penelitian, Jurusan IImu Kehutanan, Fakultas Pertanian Universitas Sumatera Utara. Medan.

Lingga P, Marsono. 2007. Petunjuk Penggunaan Pupuk. Penebar swadaya. Jakarta. $146 \mathrm{hlm}$.

Lingga, 2011, Pengaruh Cahaya Terhadap Tumbuhan, Institut pertanian Bogor. Jakarta

Mareza M, Podesta F, ratibayati. 2009. Respon Perkecambahan Lima Varietas Padi Rawa Lebak terhadap Pemberian Zat Pengatur Tumbuh 2,4-D pada Fase Vegetatif. Akta Agrosia Vol. 12(2): 177-183

Nirwan, S. 2007. Produksi Rlavonoid Daun Dewa (Gynura pseudochina (L.) DC) Asal Kultur In Vitro pada Kondisi Naungan dan Pemupukan. Disertasi Sekolah Pascasarjana, Insitut Pertanian Bogor.

Pracaya. 2011. Bertanam Mangga Di Kebun dan Pot dengan Sistem Organik. Penebar Swadaya. Jakarta.

Pracaya. 2011. Bertanam Sayur Organik. Penebar Swadaya. Jakarta. 123 h.

Prasetyo, Joko.2014. Efek Paparan Musik dan Noise pada Karakteristik Morfologi dan Produktivitas Tanaman Sawi Hijau (Brassica Juncea). Program Studi Teknik Mesin Pertanian dan Pangan, Institut Pertanian Bogor

Shihab, M. Quraish. 2002. Tafsir Al-Misbah Pesan, Kesan dan Keserasian AlQur'an. Jakarta: Lentera Hati. 
Susila, A. D. 2006. Fertigasi pada Budidaya Tanaman Sayuran Di Dalam Greenhouse. Bagian Produksi Tanaman, Departemen

Suwardi. 2010. Kajian Pengaruh Penggunaan Frekuensi Gelombang Bunyi Terhadap Pertumbuhan Benih Kedelai. Jurnal Fisika FLUX. Vol 7 (2): 170176

Wicaksono. 2008. Morfologi Tanaman Sayuran. Gajah Mada University. Press, Yogyakarta .421 hal.

Yulianto. 2008. Penerapan teknologi sonic bloom dan pupuk organik untuk peningkatan produksi bawang merah. Journal Agroland. Vol 15 (3): 148-155 